\title{
Morphology of Maxillary First Molars Analyzed by Cone-Beam Computed Tomography among Malaysian: Variations in the Number of Roots and Canals and the Incidence of Fusion.
}

\author{
Aws Hashim Al-Kadhim ${ }^{\mathrm{a}}$, Zainul Ahmad Rajion ${ }^{\mathrm{b}}$, Normaliza AB Malik ${ }^{\mathrm{a}}$, Azlan Bin Jaafar ${ }^{\mathrm{a}}$ \\ a Lecturer, Faculty of Dentistry, USIM \\ ${ }^{b}$ Associate professor, School of Dental science, USM,
}

\begin{abstract}
Introduction: A few studies investigated the numerous potential endodontic uses of $C B C T$, including the examination of root canal morphology and presumed that CBCT was effective for the initial identification of such morphology; moreover CBCT is a reliable method for the detection of the MB2 canal when compared with the gold standard of physical sectioning of the specimen. The aim of this study was to identify the root and canal morphology of the maxillary first molars among Malaysians analysed by cone-beam computed tomography $(C B C T)$ images. Materials and Methods: Maxillary first $(n=421)$ molars from Malaysian patients $(n=241)$ of Malay, Chinese and Indians inceptions were examined by two Endodontists using in vivo CBCT methods. The number and configuration of roots, the number of root canals, and the canal configuration according to Vertucci's classification were determined. Results: Single roots were not found in maxillary first molars. The incidence of fused roots was $1.995 \%$ in the first molars between mesiobuccal and distobuccal roots. In (421) 3-rooted maxillary first molars, additional canals were found in $45.6 \%$ of the mesiobuccal (MB) roots and $0 \%$ of the distobuccal (DB) roots. Bilateral symmetry of the MB roots was found in $82.36 \%$ of the first molar. Only one tooth was found to have pulp stone inside the pulp chamber. Conclusions: The root and canal configuration of a Malaysian population showed different features from those of other populations. CBCT scans can enhance the understanding of root canal anatomy, with the potential of improving the outcome of endodontic treatment.
\end{abstract}

Keywords: Canal morphology, cone-beam computed tomography, Malaysian, maxillary molars, root morphology

\section{Introduction}

Other than the customary techniques for utilizing intraoral radiograph, Cone Beam Computed Tomography (CBCT) has been proposed as a critical and approved strategy to examine the root canal morphology. ${ }^{2}$ As a superior imaging instrument, CBCT can indicate even the unpredictability of root canal morphology incorporating the molar teeth in three dimensions and has turned into the technique of choice by the dental professional particularly in endodontic treatment. ${ }^{2}$

Corresponding Author:

Dr. Aws H. Ali Al-Kadhim

Faculty of Dentistry USIM,

Level 15, Menara B, Persiaran MPAJ

Jalan Pandan Utama, Pandan Indah, 55100 Kuala

Lumpur.

Phone: 603-42892430 Fax: 603-42892522

Mobile: 016-3191490

Email:awsimail@yahoo.com
Various reviews have been distributed with respect to maxillary first molar root canals morphology utilizing different ethnic gatherings, strategies, and methodologies. Every now and again used strategies to study the root canal morphology are utilizing staining solutions, radiographic procedures and all the more as of late presented cone beam compute tomography. CBCT is a technique that uses a particular bean to create three dimensional pictures to uncover anatomic subtle elements precisely. The key points of interest of utilizing CBCT are that it is noninvasive and grants 3-D recreation of the root canals. Root morphology and properties of human tooth tissues vary among different ethnic Populaces. ${ }^{2,3}$

Since the endodontic treatment relies on upon the quality of clinical procedure, knowledge on root canal morphology is instrumental for the accomplishment of the treatment. ${ }^{3,4}$ Quantities of studies have been directed for as far back as a 
couple of years, and were not able in identifying a strong knowledge of determining root canal morphology of maxillary first molar. For the most part, the most acknowledged and accepted root canal morphology of maxillary first permanent molar is three to four canals with an additional canal was identified on the mesiobuccal root. ${ }^{5,6}$ However, studies demonstrated that maxillary first permanent molar has more unpredictable root canal framework surpassed the normal variation and has been identified utilizing a diverse set of techniques including the $\mathrm{CBCT}{ }^{7,8}$

Albeit past studies demonstrated maxillary first permanent molar with three or more mesiobuccal canals, notwithstanding, a large portion of maxillary first permanent molar tooth have 3-roots with 3 to 4 canals with additional channel situated at the mesiobuccal root. ${ }^{9,10}$ Among Asian nations, comparative conditions were accounted, for instance, in Chinese populace, Zheng et al. $^{5}$ reported the predominance was $47.2 \%$ for three canals and $50.4 \%$ for four canals. Among Korean, the prevalence of 3 -rooted was $97.9 \%$ with $63.6 \%$ having four canals. ${ }^{6}$ Besides, Peeters et al. ${ }^{11}$ reports that the predominance of four root canals among the Indonesian population was $68.5 \%$. Moreover, studies found of no association between having one or two mesiobuccal canal and gender and ethnic ${ }^{12,13}$

The aim of this study was to assess the root and canal morphology of permanent maxillary first molars and also any relationship of the conditions with gender and ethnicity in Malaysian population using $\mathrm{CBCT}$.

\section{Materials and Methods}

Data was gathered from two known public institutions and endorsed by the Ethics Committee of the School of Dental Science, Universiti Sains Malaysia (USM) and the Faculty of Dentistry, Universiti Sains Islam Malaysia (USIM). Secondary data information was retrieved from patient records on the digitized CBCT pictures of the maxillary first molar which has been gathered from patients who experienced registered tomography examining for demonstrative purposes at both University Dental Institutions. Digitized CBCT images that matched the inclusion and exclusion criteria were evaluated.

\section{Inclusion criteria:}

\section{Age between 13 and 69 years}

2. Scans containing the maxillary first molar

3. Maxillary molars with fully matured apices and without apical periodontitis

4. No root canal fillings, posts, or crown restorations
Axial, coronal, and sagittal two-dimensional section images were displayed on a monitor and inspected by two endodontists utilizing One Data Viewer software (J. Morita Manufacturing Corp). An intraexaminer calibration based on the anatomic diagnosis of CBCT images had been previously performed to assess data reliability. The two endodontists, who were assisted by a radiologist with endodontic experience, analysed 20 previously selected CBCT images of morphologically diverse maxillary first molars (three, four, and five root canals).

They assessed the images twice, with a 1-week interim between the evaluations. The reliability data were analysed with a kappa test. After intraexaminer calibration, the two endodontists separately evaluated the images in the study sample. Disagreement in the interpretation of images was first addressed in a discussion between the two endodontists. If a consensus could not be reached, a radiologist with endodontic experience helped to make the decision. The frequency of root and canal numbers; the incidence of additional canals in the MBR; and correlations with sex; and bilateral and unilateral appearance were determined and assessed by the chi square test.

During the evaluation of the samples, Vertucci's classification was taken as the main reference. Vertucci has classified root canal configuration of human permanent teeth into eight types (Figure 1) type 1 (1) - A single canal extends from the pulp chamber to the apex. Type II (2-1) - two separate canals leave the pulp chamber and join short of the apex to form one canal. Type III (1-2-1) - One canal leaves the pulp chamber, divides into two within the root, and then merges to exit as one canal. Type IV (2) - Two separate and distinct canals extend from the pulp chamber to the apex. type $V$ (1-2) - One canal leaves the pulp chamber and divides short of the apex into two separate and distinct canals with separate apical foramina. Type VI (2-1-2) - Two separate canals leave the pulp chamber, merge within the body of the root, and re-divide short of the apex to exit as two distinct canals. Type VII (1-2-1-2) - One canal leaves the pulp chamber, divides and then rejoins within the body of the root, and finally re- divides into two distinct canals short of the apex. Type VIII (3) Three separate canals extend from the pulp chamber to the apex. 

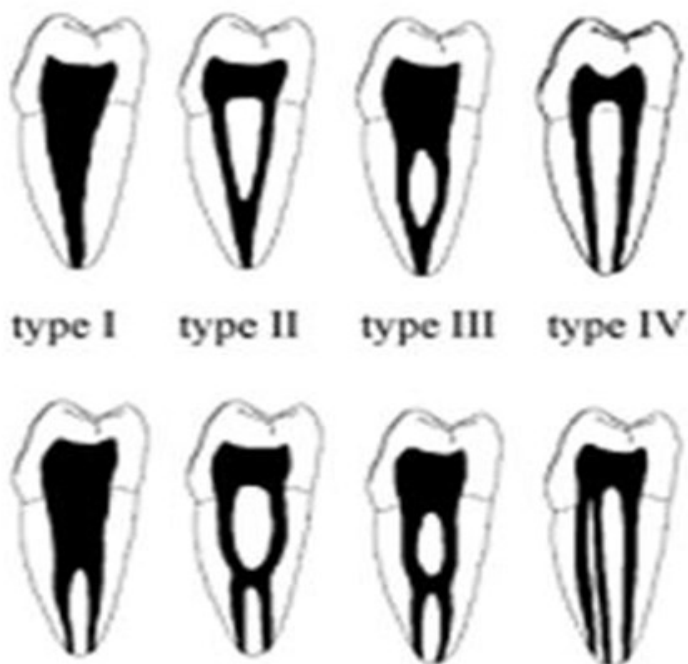

type II

type III

type IV
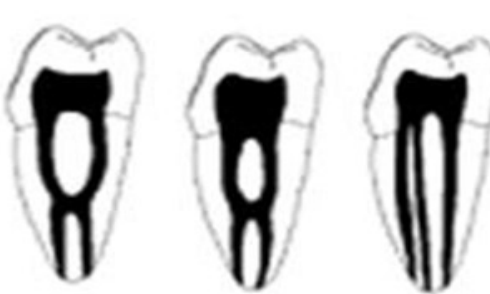

type V

\section{type VII}

\section{type VI}

\section{type VIII}

Figure 1: Vertucci's classification of canal configuration

\section{Statistical analysis}

The descriptive data were reported in the form of frequency and percentage. Meanwhile the association between the variables of mesiobuccal foramen of first maxillary molar tooth and factors related was analysed using a chi-square test. Both descriptive and association analysis was performed using SPSS software (version 20) and statistical tests were set at $p<0.05$.

\section{Results}

CBCT images of 421 maxillary molars from 241 Malaysian patients attended USIM and USM dental clinics were identified in the database; 197 of these patients had bilateral qualifying molars. Bilateral molar data were only used to analyse the distribution of unilateral and bilateral occurrence of additional canals in the MBR. The distribution of the patients, according to the race is shown as in table 1.

Table 1: Distribution of the patients according to the race

\begin{tabular}{ll}
\hline Ethnicity & No. of patient (\%) \\
\hline Malay & $178(74 \%)$ \\
Chinese & $53(22 \%)$ \\
Indians & $10(4 \%)$ \\
Total & 241 \\
\hline
\end{tabular}

Mostly, the maxillary first molars were three separated roots and about $2 \%$ of the maxillary first molar teeth showed fusion between the mesiobuccal root and disto-buccal root as shown in figure 4. The prevalence of maxillary first molar teeth of 16 and 26 with two mesio-buccal canals in this study were $45.2 \%$ and $45.0 \%$, respectively. The total percentage of maxillary molar with 2 mesio-buccal canals was $45.6 \%$ as shown in figure 1 . Whereas the prevalence of mesio-buccal root with single canal was $54.4 \%$. Bilateral symmetry of the MB roots was found in $82.4 \%$ of the first molar as shown in figure 3.

Chi-square was used to determine the relationship between the variation of mesio-buccal canals of right and left maxillary first molar teeth and their variable (Gender and ethnicity), and the results showed no significant relationship with $P$ value $>0.05$ (as shown in table 2 and 3 ) in this study.

Regarding Vertucci's classification of the root canal system of maxillary first molars, the CBCT images showed that, the commonest canal type in the mesio-buccal root was the type I (54.4\%), followed by type IV (39.5\%) and type II (6.1\%).

Table 2: The relationship between the variation of mesiobuccal canal of 16 tooth and its variables

\begin{tabular}{|c|c|c|c|c|}
\hline \multirow[t]{3}{*}{ Variable } & \multirow{2}{*}{\multicolumn{2}{|c|}{$\begin{array}{l}\text { Mes i o b u c c a l } \\
\text { foramen of } 16 \\
(n=217)\end{array}$}} & \multirow{3}{*}{$\begin{array}{l}\chi^{2} \text { test } \\
\text { (df) }\end{array}$} & \multirow[t]{3}{*}{$p$-value } \\
\hline & & & & \\
\hline & One (1) & Two (2) & & \\
\hline \multicolumn{5}{|l|}{ Gender } \\
\hline Male & $\begin{array}{ll}5 & 5 \\
(50.9)\end{array}$ & $\begin{array}{l}5 \\
(49.1)\end{array}$ & $\begin{array}{l}1.329 \\
(1)\end{array}$ & 0.249 \\
\hline Female & $\begin{array}{ll}6 & 4 \\
(58.7)\end{array}$ & $\begin{array}{l}4 \\
(41.3)\end{array}$ & & \\
\hline \multicolumn{5}{|l|}{ Ethnicity } \\
\hline Malay & $\begin{array}{ll}9 & 0 \\
(55.6)\end{array}$ & $\begin{array}{l}7 \\
(44.4)\end{array}$ & $\begin{array}{l}0.133 \\
(1)\end{array}$ & 0.716 \\
\hline Non-Malay & $\begin{array}{ll}2 & 9 \\
(52.7)\end{array}$ & $\begin{array}{ll}2 & 6 \\
(47.3)\end{array}$ & & \\
\hline
\end{tabular}

Table 3: The relationship between the variation of mesiobuccal canal of 26 tooth and its variables

\begin{tabular}{|c|c|c|c|c|}
\hline \multirow{3}{*}{ Variable } & \multirow{2}{*}{\multicolumn{2}{|c|}{$\begin{array}{l}\text { Me s i o b u c c a l } \\
\text { foramen of } 26 \\
(n=189) \\
\text { Frequency }(\%)\end{array}$}} & \multirow{3}{*}{$\begin{array}{l}\chi^{2} \text { test } \\
\text { (df) }\end{array}$} & \multirow{3}{*}{$p$-value } \\
\hline & & & & \\
\hline & One (1) & Two (2) & & \\
\hline \multicolumn{5}{|l|}{ Gender } \\
\hline Male & $49(55.7)$ & $\begin{array}{l}3 \\
(44.3)\end{array}$ & 0.029 (1) & 0.866 \\
\hline Female & $55(54.5)$ & $\begin{array}{l}4 \\
(45.5)\end{array}$ & & \\
\hline \multicolumn{5}{|l|}{ Ethnicity } \\
\hline Malay & $80(58.0)$ & $\begin{array}{ll}5 & 8 \\
(42.0)\end{array}$ & 1.792 (1) & 0.181 \\
\hline $\begin{array}{l}\text { Non- } \\
\text { Malay }\end{array}$ & $24(47.1)$ & $\begin{array}{ll}2 & 7 \\
(52.9)\end{array}$ & & \\
\hline
\end{tabular}




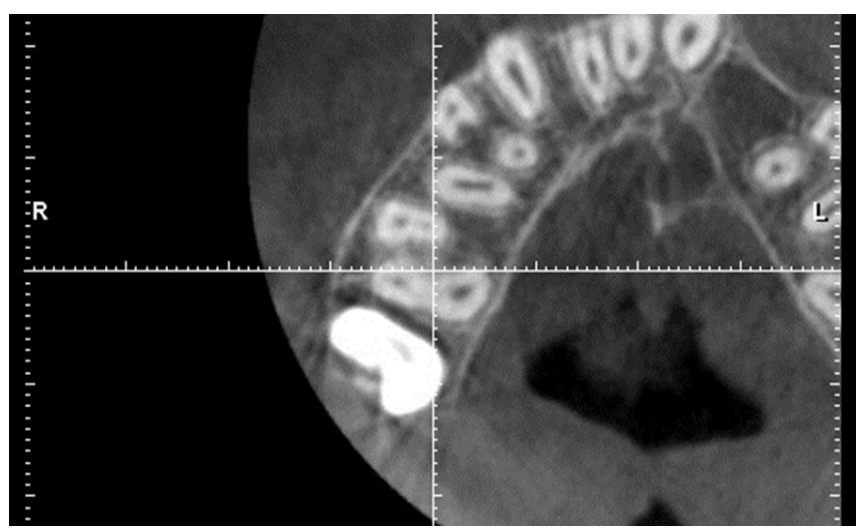

Figure 2: Maxillary first molar with two mesio-buccal canals.

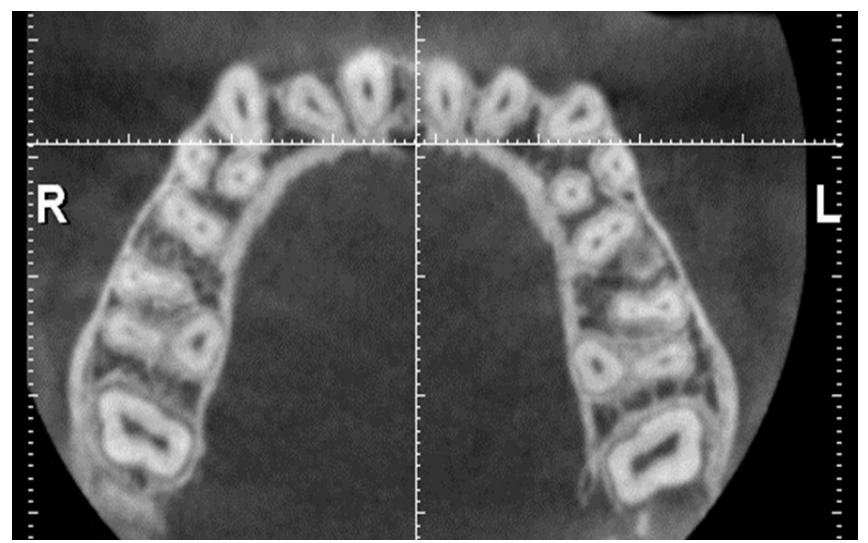

Figure 3: Bilateral symmetry of maxillary first molar with two mesio-buccal canals in 23 year old malay female.

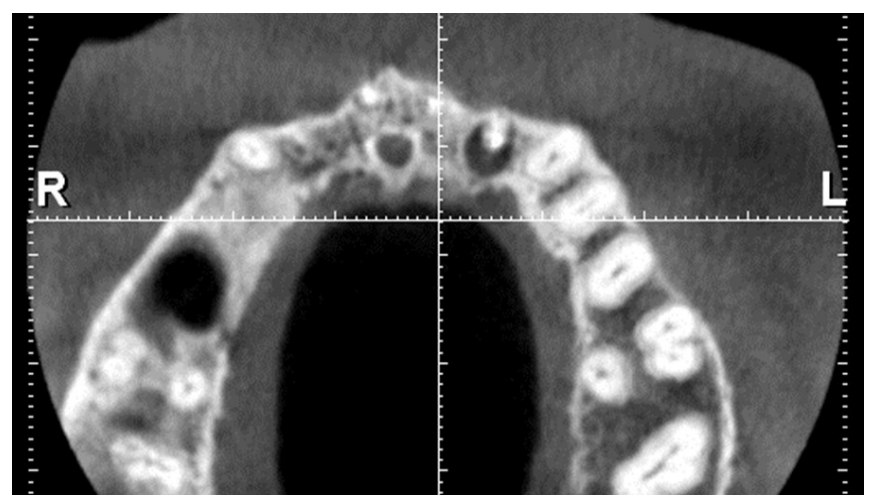

Figure 4: Incidence of fusion between mesio-buccal and disto-buccal roots of maxillary first molar among Malaysian population.

\section{Discussion}

A careful information about the root and canal anatomy of maxillary first molar encourages the exact recognition of all root canals in a tooth during endodontic therapy. Several articles of the tooth and canal morphology of maxillary first molar have been directed in light of the fact that this specific tooth presents complex and unique morphology, that makes root canal therapy more challenging. ${ }^{14,15}$ However, most of the prior studies have either completely or partially destroyed the tooth during examination or have gained only two-dimensional anatomic information. Moreover, few studies have incorporated information such as ethnic background and sex of the study population, ${ }^{12,3}$ which may have critical clinical ramifications for treatment.

The significance of knowledge about the anatomic morphology of the maxillary molars and possible variations is effective for successful endodontic therapy and cannot be denied. The current study gives a definite provide details regarding the morphology of root canal of maxillary first molars in Malaysian populace utilizing $\mathrm{CBCT}$.

The recent utilization of $C B C T$ has made it conceivable to lead a nondestructive 3D global analysis of the external and internal morphology of the root and canal system. The Planmeca ProMax 3D Mid CBCT machine used in this study offers high resolution and is well suited for endodontic applications.

This study found that $2 \%$ of maxillary first molars among Malaysian patients had fused roots as shown in figure 4. The MBR had a higher frequency of fusion than other roots. This result was consistent with findings in Ugandan ${ }^{16}$ and, to a lesser extent, Irish populations. ${ }^{17}$ However, previous studies of Burmese $^{18}$ and Thai populations ${ }^{(14)}$ found three separate roots in all maxillary first molars. These differences highlight the influence of ethnic background on maxillary molar root morphology.

The percentage of the extra mesiobuccal canal (MB2) in the MBR has been accounted for by numerous studies as shows in table 4 . In comparison to current study, high frequency $(45.60 \%)$ of additional MBR canals is largely consistent with findings from clearing studies of Asian populations from China and Japan (58.0\%) but lower than Turkish population $(93.5 \%){ }^{14,19,20}$

In this study, we observed a wide variation of canal morphology in the MB root. Two canals were found in $45.6 \%$ of the cases as shown in figure 2 . In this way, our result has close affinities with those of the populations of China and Japan ${ }^{(5,29)}$. However, the result of this study seems lower than those in the neighbouring nations such as Indonesia and Thailand. ${ }^{11,}{ }^{14}$ These distinctions highlight the impact of ethnic foundation on maxillary molar root morphology.

The main concern for endodontists remains the number of canals inside each root. This study has reported palatal and distobuccal roots contain single canal (100\% of cases). The incidence of two palatal canals is very rare. ${ }^{32}$ Cleghorn et al. has conducted a comprehensive review of the anatomy of the 
permanent maxillary 1st molar. All included studies in this review analysed more than 8400 teeth collectively and reported very rare incidence of two palatal roots/canal. ${ }^{33}$ Similar findings have been reported for the distal root, one canal in $(100 \%)$ of cases in the current study and many other studies. However, a very low incidence $(0.1-4 \%)$ of two or more canals has been reported ${ }^{17}$ in a study that used the clearing method among the Irish population. Sert and Bayirli ${ }^{20}$ conducted a clearing investigation of human permanent teeth from Turkish patients and concluded that sex was an imperative variable to consider in the preoperative assessment of canal morphology for nonsurgical RCT. Interestingly, the incidence of additional MBR canals in our sample did not vary by the sex of the patient. This is in concordance with the results of a previous study reported by Neaverth et al. ${ }^{31}$ and Zheng et al. ${ }^{5}$ We additionally found that the number of MBR canals was not influenced by tooth position, which is in agreement with the latter studies.

Additional MBR canals were symmetrically conveyed in $82.36 \%$ of our Malaysian population as shown in figure 3. If a patient has a known MB2 in one maxillary first molar, the dentist should be aware of the likelihood that an MB2 is present in the opposite molar. We found no differences in bilateral occurrence by sex or tooth position. This result is in agreement with Zheng et al. ${ }^{5}$ whose conducted the study among Chinese population.

There is not even a single study denying the existence of second canal maxillary first molars. ${ }^{5}$ This is very clear from the above discussion that the internal anatomy of maxillary 1st molar particularly the mesiobuccal root has never been straightforward. There is a high frequency of two or more canals system in the mesiobuccal root and diverges broadly based on factors such as racial ethnicity, population and configuration. The configuration of root canals make it further complicated as six different types of configuration has been classified by Vertucci's. In the current study, two configuration types (Vertucci's type II, IV) were observed for two canals and only type I was observed for single canal roots.

Table 4: The percentage of extra mesiobuccal canal (MB2) in the MBR by numerous studies.

\begin{tabular}{|c|c|l|}
\hline $\begin{array}{c}\text { Prevalence of MB2 } \\
(\%)\end{array}$ & \multicolumn{1}{|c|}{ Country } & \multicolumn{1}{|c|}{ Authors } \\
\hline 90.0 & New Zealand & Verma and Love (21) \\
\hline 86.5 & Serbia & Beljić-Ivanović and Teodorović (22) \\
\hline 81.3 & India & Chopra and Bal (23) \\
\hline 80.0 & Italy & Somma et al. (24) \\
\hline 79.8 & United States of America & Degerness and Bowles (19) \\
\hline 78.0 & Turkey & Alaçam et al. (25) \\
\hline 78.0 & German & Schwarze et al. (26) \\
\hline 78.0 & Ireland & Al Shalabi et al. (17) \\
\hline 77.3 & Jordan & Smadi and Khraisat (27) \\
\hline 775.0 & Uganda & Rwenyonyi et al. (16) \\
\hline 71.8 & Korea & Lee et al. (28) \\
\hline 68.5 & Indonesia & Peeters et al. (11) \\
\hline 66.7 & Burma & Ng et al. (15) \\
\hline 65.0 & Thailand & Alavi et al. (14) \\
\hline 55.6 & Japan & Yamada et al. (29) \\
\hline 52.2 & China & Zheng et al. (5) \\
\hline 45.6 & Malaysia & Current study \\
\hline 22.0 & Nigeria & Abiodun-Solanke et al. (30) \\
\hline & & \\
\hline & & \\
\hline & &
\end{tabular}




\section{CONCLUSION}

This study showed that the root canal morphology of the $M B$ root is highly variable and frequently has more than one canal. We found that the prevalence of MB2 was $45.6 \%$ in a Malaysian population. Root canal morphology of maxillary first molars of Malaysians is consistent with that of the people of China and Japan population groups and far different from the people of Sub Saharan African populations. The present study further strengthens the idea that the root canal morphology is variable in different population groups. It is in this way essential to be acquainted with these varieties because they ultimately may have both clinical and anthropological noteworthiness. Such knowledge can aid in the location and negotiation of canals as well as their subsequent management in clinical practice and even tracing the origins of world populations. Even though the results of various ethnic studies cited, vary widely, the lesson here is that the prevalence of the MB2 exists in every population and should be strongly considered when treating maxillary first molar.

\section{REFERENCES}

1. Michetti J, Maret D, Mallet J-P, Diemer F. Validation of cone beam computed tomography as a tool to explore root canal anatomy. Journal of endodontics. 2010;36(7):1187-90.

2. Nur BG, Ok E, Altunsoy M, Aglarci OS, Colak M, Gungor E. Evaluation of the root and canal morphology of mandibular permanent molars in a south-eastern Turkish population using conebeam computed tomography. European journal of dentistry. 2014;8(2):154.

3. Ashraf $H$, Paymanpour $P$, Bidabadi MM, Hajrezai R. Healing of an extensive periradicular lesion subsequent to a proper endodontic treatment of a mandibular first premolar with complex anatomy. Case reports in dentistry. 2013;2013.

4. Chang S, Lee J, Lee $Y$, Kum K. In-depth morphological study of mesiobuccal root canal systems in maxillary first molars: review. Restor Dent Endod. 2013; 38 (1): 2-10. PMid: 23493453 PMCid: PMC3591580. dx doi org/105395/rde. 2013;1.

5. Zheng Q-h, Wang $\mathrm{Y}$, Zhou X-d, Wang Q, Zheng G-n, Huang D-m. A cone-beam computed tomography study of maxillary first permanent molar root and canal morphology in a Chinese population. Journal of endodontics. 2010;36(9):1480-4.

6. Kim Y, Chang S-W, Lee J-K, Chen I-P, Kaufman $\mathrm{B}$, Jiang $\mathrm{J}$, et al. A micro-computed tomography study of canal configuration of multiplecanalled mesiobuccal root of maxillary first molar. Clinical oral investigations. 2013;17(6):1541-6.

7. Abuabara A, Cruz GV, Correa CGL, Guerino L, Baratto Filho F. Identification of root canals in maxillary molars using cone beam computed tomography. RSBO (Online). 2010;7(1):117-20.

8. Kumar R. Report of a rare case: a maxillary first molar with seven canals confirmed with conebeam computed tomography. Iranian endodontic journal. 2014;9(2):153.

9. Shahi S, Yavari HR, Rahimi S, Ahmadi A. Root canal configuration of maxillary first permanent molars in an Iranian population. Journal of dental research, dental clinics, dental prospects. 2007;1(1):1-5.

10. Bhuyan AC, Kataki R, Phyllei P, Gill GS. Root canal configuration of permanent maxillary first molar in Khasi population of Meghalaya: An in vitro study. Journal of conservative dentistry: JCD. 2014;17(4):359.

11. Peeters HH, Suardita K, Setijanto D. Prevalence of a second canal in the mesiobuccal root of permanent maxillary first molars from an Indonesian population. Journal of oral science. 2011;53(4):489-94.

12. Tinelli M, Ferreira G, Llahyah K, Gomez N. Ethnic Variations in the topography of the root canals. 2011.

13. Kazemipoor M, Hajighasemi A, Hakimian R. Gender difference and root canal morphology in mandibular premolars: A cone-beam computed tomography study in an Iranian population. Contemporary clinical dentistry. 2015;6(3):401.

14. Alavi A, Opasanon A, Ng YL, Gulabivala K. Root and canal morphology of Thai maxillary molars. International Endodontic Journal. 2002;35(5):478-85.

15. Pineda F, Kuttler Y. Mesiodistal and buccolingual roentgenographic investigation of 7,275 root canals. Oral Surgery, Oral Medicine, Oral Pathology. 1972;33(1):101-10.

16. Rwenyonyi C, Kutesa A, Muwazi L, Buwembo W. Root and canal morphology of maxillary first and second permanent molar teeth in a Ugandan population. International Endodontic Journal. 2007;40(9):679-83.

17. Al Shalabi R, Omer JG, Jennings M, Claffey N. Root canal anatomy of maxillary first and second permanent molars. International Endodontic Journal. 2000;33(5):405-14.

18. Ng YL, Aung T, Alavi A, Gulabivala K. Root and canal morphology of Burmese maxillary molars. International Endodontic Journal. 2001;34(8):620-30. 
19. Degerness RA, Bowles WR. Dimension, anatomy and morphology of the mesiobuccal root canal system in maxillary molars. Journal of endodontics. 2010;36(6):985-9.

20. Sert S, Bayirli GS. Evaluation of the root canal configurations of the mandibular and maxillary permanent teeth by gender in the Turkish population. Journal of endodontics. 2004;30(6):391-8.

21. Verma P, Love R. A Micro CT study of the mesiobuccal root canal morphology of the maxillary first molar tooth. International Endodontic Journal. 2011;44(3):210-7.

22. Beljić-Ivanović K, Teodorović N. Morphological characteristics of mesiobuccal root canals of the first maxillary molars. Srpski arhiv za celokupno lekarstvo. 2010;138(7-8):414-9.

23. Chopra P, Bal C. Study of root canals and their configuration in buccal roots of maxillary first permanent molar. Indian journal of dental research: official publication of Indian Society for Dental Research. 1988;1(1):3-14.

24. Somma F, Leoni D, Plotino G, Grande N, Plasschaert A. Root canal morphology of the mesiobuccal root of maxillary first molars: a micro-computed tomographic analysis. International Endodontic Journal. 2009;42(2):165-74.

25. Alaçam T, Tinaz AC, Genç Ö, Kayaoglu G. Second mesiobuccal canal detection in maxillary first molars using microscopy and ultrasonics. Australian Endodontic Journal. 2008;34(3):106-9.

26. Schwarze $T$, Baethge $C$, Stecher $T$, Geurtsen $W$. Identification of second canals in the mesiobuccal root of maxillary first and second molars using magnifying loupes or an operating microscope. Australian Endodontic Journal. 2002;28(2):57-60.

27. Smadi L, Khraisat A. Detection of a second mesiobuccal canal in the mesiobuccal roots of maxillary first molar teeth. Oral Surgery, Oral Medicine, Oral Pathology, Oral Radiology, and Endodontology. 2007;103(3):e77-e81.

28. Lee J-H, Kim K-D, Lee J-K, Park W, Jeong JS, Lee $Y$, et al. Mesiobuccal root canal anatomy of Korean maxillary first and second molars by cone-beam computed tomography. Oral Surgery, Oral Medicine, Oral Pathology, Oral Radiology, and Endodontology. 2011;111(6):785-91.

29. Yamada $M$, Ide $Y$, Matsunaga $S$, Kato $H$, Nakagawa K-I. Three-dimensional analysis of mesiobuccal root canal of Japanese maxillary first molar using Micro-CT. The Bulletin of
Tokyo Dental College. 2011;52(2):77-84.

30. Abiodun-Solanke IMF, Dosumu OO, Shaba PO, Ajayi DM. Prevalence of additional canals in maxillary first molars in a Nigerian population. J Contemp Dent Pract. 2008;9(81):8.

31. Neaverth EJ, Kotler LM, Kaltenbach RF. Clinical investigation (in vivo) of endodontically treated maxillary first molars. Journal of endodontics. 1987;13(10):506-12.

32. Christie W, Peikoff M, Fogel H. Maxillary molars with two palatal roots: A retrospective clinical study. J Endod. 1991;17:(2)80-84.

33. Cleghorn BM, Christie WH, Dong CCS. Root and root canal morphology of the human permanent maxillary first molar: A literature review. J Endod. 2006;32:(9)813-821. 